\title{
Roles of Circulating WNT-Signaling Proteins and WNT-Inhibitors in Human Adiposity, Insulin Resistance, Insulin Secretion, and Inflammation
}

\begin{abstract}
Authors
\end{abstract}
Affiliations

\author{
R. U. Almario ${ }^{1}$, S. E. Karakas ${ }^{1,2}$
}

${ }^{1}$ Department of Internal Medicine, Division of Endocrinology, Diabetes and Metabolism, The University of California at Davis, Davis, CA, USA

${ }^{2}$ Department of Veterans Affairs Northern California Health Care System, Mather, CA, USA

Key words
WNT5
WISP2
SFRP4
SFRP5
PCOS
obesity
insulin resistance

received 17.03 .2014 accepted 16.06.2014

\section{Bibliography}

DOI http://dx.doi.org/

10.1055/s-0034-1384521

Published online:

August 4, 2014

Horm Metab Res 2015;

47: 152-157

(c) Georg Thieme Verlag KG Stuttgart · New York ISSN 0018-5043

\section{Correspondence}

S. E. Karakas, MD

Professor and Chief

Division of Endocrinology,

Diabetes and Metabolism

4150V. Street

PSSB G400 Sacramento

CA 95817

USA

Tel.: + 1/916/7343730

Fax: + 1/916/734 7953

sekarakas@ucdavis.edu

\section{Abstract \\ $\nabla$}

Wingless-type MMTV integration site family member (WNT) signaling and WNT-inhibitors have been implicated in regulation of adipogenesis, insulin resistance, pancreatic function, and inflammation. Our goal was to determine serum proteins involved in WNT signaling (WNT5 and WISP2) and WNT inhibition (SFRP4 and SFRP5) as they relate to obesity, serum adipokines, insulin resistance, insulin secretion, and inflammation in humans. Study population comprised 57 insulin resistant women with polycystic ovary syndrome (PCOS) and 27 reference women. In a cross-sectional study, blood samples were obtained at fasting, during oral, and frequently sampled intravenous glucose tolerance tests. Serum WNT5, WISP2, and SFRP4 concentrations did not differ between PCOS vs. reference women. Serum WNT5 correlated inversely with weight

\section{Introduction}

$\nabla$

Wingless-type MMTV integration site family member (WNT) signaling has been implicated in regulation of adipogenesis, insulin resistance, pancreatic function, and inflammation [1-3]. Proteins involved in WNT signaling (WNT and WNT-inducible secreted protein 2: WISP2) as well as WNT inhibition (secreted frizzled-related proteins 4 and 5: SFRP4 and SFRP5) are secreted into the circulation. Although limited number of clinical studies linked one or more of these serum proteins to various metabolic disorders, these proteins have not been evaluated systematically in a single study.

Role of WNT signaling in adipogenesis has been investigated in experimental studies [4-8]. Canonical WNT signaling inhibits both commitment of mesenchymal stem cells into preadipocytes and differentiation of preadipocytes into adipocytes $[4,5]$. This occurs through a step-by- both in PCOS and reference women, and correlated directly with insulin response during oral glucose tolerance test in PCOS women. Serum WISP2 correlated directly with fatty acid binding protein 4. Serum SFRP5 did not differ between obese $(n=32)$ vs. nonobese $(n=25)$ PCOS women, but reference women had lower SFRP5 ( $p<5 \times 10^{-6}$ as compared to both PCOS groups). Serum SFRP5 correlated inversely with IL-1 $\beta$, TNF- $\alpha$, cholesterol, and apoprotein B. These findings demonstrated that WNT5 correlated inversely with adiposity and directly with insulin response, and the WNT-inhibitor SFRP5 may be anti-inflammatory. Better understanding of the role of WNT signaling in obesity, insulin resistance, insulin secretion, lipoprotein metabolism, and inflammation is important for prevention and treatment of metabolic syndrome, diabetes and cardiovascular disease.

step process: First, WNT activation induces production of the cytosolic protein WISP2. Next, WISP2 binds to a transcriptional activator complex called zinc finger protein (ZNF) 423/Ffp423 in the cytosol and prevents it from moving to the nucleus. Since ZNF423/Ffp423 is an activator of peroxisome proliferator-activated receptor (PPAR)r, trapping of this complex in the cytosol interferes with PPAR $\gamma$ activation [1]. Since PPARY is required for adipogenesis, activation of WNT signaling inhibits adipogenesis. Consequently, WNT activation limits storage function of the adipose tissue and diverts the lipids to liver and muscle, leading to metabolic complications of obesity such as insulin resistance and fatty liver disease $[1,9]$. In addition, WNT signaling increases insulin resistance by activating c-Jun $\mathrm{N}$-terminal kinase (JNK) cascade, JUN kinase, and serine phosphorylation of IRS-1 through the noncanonical signaling pathway [10]. 
Recent studies indicated that WNT signaling plays an important role in the inflammatory events, which link obesity to its metabolic complications as well. Macrophages, which reside in the adipose tissue, secrete the proinflammatory WNT5 glycoprotein. In response, healthy adipocytes produce the SFRP5, which sequesters WNT5 in the extracellular space and prevents its binding to the receptor [10]. Thus, SFRP5 serves as an antiinflammatory adipokine, which promotes insulin sensitivity and reduces metabolic dysfunction $[3,8,11]$. Consistent with this compensatory response, SFRP5 expression was found to be increased in several genetic as well as experimental mouse models of obesity and correlated with the adipocyte size [3]. In humans, there have been conflicting reports. Limited number of studies carried out in diverse populations reported decreased as well as increased SFRP5 levels in obesity and insulin resistance $[12,13]$.

Another secreted frizzled-related protein (SFRP4) has been implicated in type 2 diabetes (DM) through analysis of global gene expression studies. In these investigations SFRP4 gene expression in pancreatic islet cells was found to be highly associated with type 2 DM and correlated strongly with HbA1c and insulin secretion [14]. Additional research indicated that SFRP4 inhibited WNT signaling and reduced insulin secretion by decreasing calcium influx and insulin exocytosis in islet cells [14]. Moreover, serum SFRP4 concentrations were found to be elevated in type 2 DM, even before the development of overt hyperglycemia [14].

Our study included women with polycystic ovary syndrome (PCOS) because these women frequently have insulin resistance and pancreatic dysfunction [15]. Polycystic ovary syndrome is a common disorder affecting $6-10 \%$ of young women; approximately $60 \%$ of PCOS patients have metabolic syndrome; one out of 5 develops diabetes before the age of 40 years [16-18]. Biochemical mechanisms underlying the abnormal glucose homeostasis have been reviewed in detailed in recent as well as earlier publications $[15,19]$. The metabolic disorders commonly associated with PCOS have been linked to increased WNT-signaling in experimental studies. Therefore, we investigated serum WNT5, WISP2, SFRP5, and SFRP4 as they relate to obesity, insulin resistance, glucose-stimulated insulin response, and inflammation in PCOS. Based on the published literature, we anticipated that serum WNT5 and WISP2 would relate to insulin resistance $[7,11]$ and possibly to insulin response $[20,21]$; SFRP5 to insulin sensitivity $[3,8,11]$; and SFRP4 to impairment of first phase of insulin secretion [12].

\section{Subjects and Methods \\ $\nabla$}

The study was approved by the Institutional Review Board of University of California, Davis, USA. All subjects signed informed consents. The investigators did not have any conflict of interest. Women between the ages $20-45$ years and with a body mass index (BMI) of $25-45 \mathrm{~kg} / \mathrm{m}^{2}$ who fulfilled the $\mathrm{NIH}$ criteria for PCOS by having ovarian dysfunction, as evidenced by amenorrhea (no periods for $>6$ months) or oligomenorrhea ( $<6$ periods/year), clinical (hirsutism), or laboratory evidence for hyperandrogenemia (total testosterone $>54 \mathrm{ng} / \mathrm{dl}$ or free testosterone $>9.2 \mathrm{pg} / \mathrm{ml}$ ), along with the absence of any confounding clinical pathology (i.e., Cushing's disease, 21 hydroxylase deficiency, or prolactinoma) were recruited. Patients were excluded if they used oral contraceptives, anti-androgenic medi- cations, insulin sensitizers, d-chiro-inositol, or any other medications or supplements that affect weight or insulin sensitivity during the preceding 2 months; had diabetes mellitus, untreated hypothyroidism or thyroid disease, and any other systemic illness such as renal, hepatic, and gastrointestinal disease; smoke; or drink $>2$ alcoholic drinks per week. Menstruating women were tested during the follicular phase of the cycle.

To obtain reference values for serum WNT5, WISP2, SFRP5, and SFRP4, fasting blood samples were obtained from healthy women who did not have any of the exclusion criterion mentioned for the PCOS patients. These women had regular menstrual cycles and the blood samples were obtained during the follicular phase of their cycles.

Studies were carried out at the Clinical and Translational Science Center Clinical Research Center of the University of California, Davis (CCRC), USA. All studies were conducted after an overnight fast, before $9 \mathrm{AM}$. Weight was measured in light clothing using the Tanita BWB800-P Digital Medical Scale. Body composition was determined using bioelectrical impedance. The oral glucose tolerance tests (OGTT) and frequently sampled intravenous glucose tolerance tests (FS-IGT) were performed one week apart.

\section{OGTT}

After obtaining the baseline samples; participants drank $75 \mathrm{~g}$ of glucose (Glucola ${ }^{\mathrm{TM}}$ ) and additional blood samples were obtained every $30 \mathrm{~min}$ for $2 \mathrm{~h}$.

\section{FS-IGT}

An intravenous catheter was placed in the forearm and kept open with normal saline. Heating pads were used in order to maximize blood flow. Three blood samples were obtained at times $-15,-10$, and $-5 \mathrm{~min}$. Glucose $(0.3 \mathrm{~g} / \mathrm{kg}$ as $25 \%$ dextrose $)$ was given intravenously at time $0 \mathrm{~min}$. Intravenous insulin $0.03 \mu / \mathrm{kg}$ (Humulin Regular: Eli Lilly) was given at time $20 \mathrm{~min}$ after the glucose administration. Blood samples were obtained at times $0,2,3,4,5,6,8,10,12,14,16,19,22,23,24,25,27,30$, $40,50,60,70,90,100,120,140,160$, and $180 \mathrm{~min}$. Acute insulin response to glucose (AIR Glucose: $_{\text {an }}$ index of insulin secretion), $\beta$-cell function, sensitivity index (SI), and disposition index (DI) were calculated using MiniMod Millennium software (Dr. Bergman, Los Angeles, CA, USA).

\section{Biochemical measurements}

Glucose was measured using YSI 2300 STAT Plus Glucose \& Lactate Analyzer (YSI Life Sciences, Yellow Springs, OH, USA), with a coefficient of variation (CV) of $1 \%$. Insulin was measured by RIA (Milipore, St. Charles, MO, USA) with a CV of $8.2 \%$. Triglyceride, cholesterol, and HDL-cholesterol were measured using PolyChem System Analyzer (Cortlandt Manor, NY, USA) with CVs of $3.5 \%, 4 \%$, and $3.6 \%$, respectively. Leptin and adiponectin were measured using RIA (Millipore, St. Charles, MO, USA) with CVs of $4.3 \%$ and $6.5 \%$. hs-CRP was measured using a highly sensitive (hs) latex-enhanced immunonephelometric assay (Beckman UniCel DxC 800 systems; Beckman-Coulter, Brea, CA, USA) with a $\mathrm{CV}<5 \%$. Total testosterone, sex hormone binding globulin (SHBG), and DHEAS were measured by RIA (Diagnostic Systems Laboratories, Webster, TX, USA) with CVs of $8.3 \%, 4.4 \%$, and $9.6 \%$, respectively. Serum SFRP4 was measured by ELISA (MyBioSource, Atlanta, GA, USA) with CV of 9.8\%; SFRP5 by ELISA (USCN Life Science, Inc., Burlington, ON, USA) with CV of $9 \%$; WNT5 by ELISA (Antibodies-Online, Atlanta, GA, USA) with CV of $8 \%$, WISP2 by ELISA (MyBioSource, Atlanta, GA, USA) with CV of $<15 \%$. 


\section{Calculations}

Peripheral insulin resistance was assessed by calculating Mat-

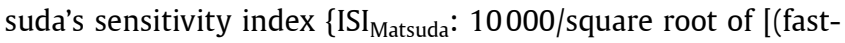
ing glucose $\times$ fasting insulin $) \times($ mean glucose $\times$ mean insulin during OGTT)] $\}$ and SI by applying the MINIMOD program to FSIGT data. Hepatic insulin resistance was assessed by calculating Homeostasis Model Assessment \{HOMA: [(fasting insulin $(\mu \mathrm{U} /$ $\mathrm{ml}) \times$ fasting glucose $(\mathrm{mg} / \mathrm{dl})] / 405$ \}. Early insulin secretion was assessed by calculating AIRg from FS-IGT. Pancreatic function was assessed by calculating the area under the curve (AUC) for insulin during OGTT and calculating $\beta$-cell function during FSIGT. $\beta$-cell compensation for insulin resistance was assessed by calculating DI from AIRg and SI.

\section{Statistical analysis}

The SPSS software, version 9.1 (SAS Institute Inc, Cary, NC, USA) was used. Descriptive statistics were calculated for each variable. When necessary, the data were log-transformed in order to improve the normality of residuals and homoscedasticity of errors where appropriate before analysis. The groups were compared by conducting nonparametric multiple comparisons. For significant variables, this was followed by Wilcoxon comparisons in order to determine the pairs of variables accounting for the significance. Correlations were analyzed using nonparametric Spearman's analysis. Partial correlations were calculated after accounting for a relevant variable. Significance was set at $\mathrm{p}<0.05$.

\section{Results}

$\nabla$

\section{Clinical characteristics of study groups ( 0 Table 1,2 )}

The reference women were older than the PCOS women. There were no other significant age differences among the groups. Since weight is a significant determinant of insulin resistance, women with PCOS were evaluated in 2 groups: nonobese $(n=25)$ and obese $(n=32)$. The nonobese PCOS group matched the reference women for weight and BMI. As expected, obese PCOS women had higher BMI, fat-mass, and serum leptin.

Obese as well as nonobese PCOS women were more insulin resistant as compared to reference women based on fasting insulin levels. Obese-PCOS women were more insulin resistant than nonobese PCOS women based on HOMA ( $<<0.0002)$. Reference women had higher adiponectin as compared to obese PCOS women $(p=0.001)$. Reference women also had higher HDL-cholesterol than both obese and nonobese PCOS women ( $p<1 \times 10^{-4}$ for both). Reference women had lower hs-CRP than the nonobese PCOS women $(p=0.008)$. Obese-PCOS women also had higher triglyceride as compared to nonobese PCOS women $(\mathrm{p}=0.002)$. As shown in $\odot$ Table 2, OGTT and FS-IGT confirmed that obese-PCOS women were more insulin resistant than nonobese PCOS women (Matsuda-SI: $\mathrm{p}=0.0003$; FS-IGT-SI: $\mathrm{p}=0.055)$.

\section{Fasting serum WNT5, WISP2, SFRP5, and SFRP4} (o Table 1, 2)

As shown in $\odot$ Table 1, serum WNT5, WISP2, or SFRP4 concentrations did not differ among the groups. Reference women had significantly lower SFRP5 as compared to both obese and nonobese PCOS women ( $<<5 \times 10^{-6}$ for both) while there was no difference between the serum SFRP5 concentrations of obese versus nonobese PCOS groups.
Correlations between WNT5, WISP2, SFRP5, SFRP4, and other clinical and biochemical variables ( 0 Table 3 )

In the entire PCOS group $(n=57)$, WNT5 tended to correlate inversely with weight $(r=-0.228, p=0.087)$, fat-mass $(r=-0.236$, $\mathrm{p}=0.078)$, and leptin $(\mathrm{r}=-0.235, \mathrm{p}=0.081)$. WNT5 correlated directly with the area under the curve for insulin $\left(\mathrm{AUC}_{\mathrm{Insulin}}\right)$ and the 90-min insulin concentration during OGTT; WNT5 tended to correlate with the inflammatory marker IL-6 $(r=0.277, \mathrm{p}=0.056)$. After controlling for BMI, the correlation between the 90-min insulin response and WNT5 remained significant.

In the entire PCOS group, serum WISP2 correlated directly with SFRP4 and fatty acid binding protein 4 . Serum SFRP5 correlated inversely with the inflammatory markers IL-1 $\beta$ and TNF- $\alpha$ as well as with the atherogenic lipids such as cholesterol and apoprotein B. Serum SFRP5 also tended to correlate inversely with fasting glucose $(r=-0.253 ; p=0.058)$. Serum SFRP4 did not correlate with any of the insulin secretion parameters measured by FS-IGT or OGTT, or any lipids or inflammatory markers but correlated directly with DHEAS.

Since nonobese PCOS women and reference women had similar body weights but had very different insulin resistance states, correlations between serum WNT5, WISP2, SFRP4 and SFRP4, and metabolic parameters were investigated by considering nonobese PCOS women and reference women as a single group $(n=52)$. Over the wide spectrum of insulin resistance, serum WNT5, WISP2, SFRP4, and SFRP5 showed no correlations with fasting glucose, fasting insulin, HOMA or adiponectin. However, WNT5 correlated inversely with the parameters of adiposity (BMI: $\mathrm{r}=-0.335, \mathrm{p}=0.015$, fat-mass: $\mathrm{r}=-0.400, \mathrm{p}=0.003$; leptin: $r=-0.304, p=0.03)$ as well as age $(r=-0.364, p=0.009)$. Serum SFRP5 correlated inversely with total cholesterol $(r=-317$, $\mathrm{p}=0.014)$ and tended to correlate inversely with age $(\mathrm{r}=-0.240$, $\mathrm{p}=0.089$ ). After controlling for age, the correlation with total cholesterol weakened $(r=-0.257, p=0.078)$. For SFRP4, controlling for age improved the previously nonsignificant correlations for triglyceride $(r=0.359, p=0.012)$ and hs-CRP $(r=0.271, p=0.062)$.

\section{Discussion}

$\nabla$

Among PCOS women, serum WNT5 tended to correlate inversely with weight and fat-mass and correlated directly with insulin response during OGTT. In general, obesity is associated with hyperinsulinemia. In PCOS, WNT5 tended to relate inversely to obesity but related directly hyperinsulinemia. The inverse relationship between obesity and serum WNT5 is consistent with the anti-adipogenic effect of WNT signaling as presented earlier [7,22-25]. The direct relationship to hyperinsulinemia may have 2 potential explanations. First, WNT signaling plays a role in the development of endocrine pancreas and regulates $\beta$-cell function [21]. Specifically WNT5 potentiates glucose-stimulated insulin secretion $[26,27]$. WNT signaling is increased in the pancreas of patients with Type 2 DM [20]. Thus, WNT5 may contribute to increased insulin response seen in PCOS. Alternatively, hyperinsulinemia is a compensatory response to insulin resistance and delayed insulin response to glucose is associated with development of glucose intolerance in PCOS [28]. Thus, the correlation seen between WNT5 and $\mathrm{AUC}_{\text {Insulin }}$ and late insulin response during OGTT may suggest that WNT5 plays a role in the development of insulin resistance and glucose intolerance in PCOS. Since WNT5 did not relate to any of the insulin resistance 


\begin{tabular}{|c|c|c|c|}
\hline & Obese PCOS (n= 32$)$ & Nonobese PCOS $(n=25)$ & Reference women $(n=27)$ \\
\hline \multicolumn{4}{|c|}{ Anthropometric Variables } \\
\hline Age (years) & $31.7 \pm 6.4$ & $32.8 \pm 6.8$ & $44.5 \pm 12.9^{\mathrm{a}, \mathrm{b}}$ \\
\hline Weight (kg) & $114.1 \pm 14.0$ & $73.9 \pm 10.5$ & $73.7 \pm 8.3$ \\
\hline $\operatorname{BMI}\left(\mathrm{kg} / \mathrm{m}^{2}\right)$ & $40.6 \pm 5.6$ & $28.7 \pm 4.4^{\mathrm{a}}$ & $27.6 \pm 2.3^{a}$ \\
\hline Fat mass $(\mathrm{kg})$ (\% fat) & $56.3 \pm 67.3(49.3 \pm 58.9)$ & $27.0 \pm 8.4^{\mathrm{a}}(36.5 \pm 11.4)$ & $29.0 \pm 6.3^{\mathrm{a}}(39.3 \pm 8.5)$ \\
\hline \multicolumn{4}{|c|}{ Fasting Plasma Variables } \\
\hline WNT5 (ng/ml) & $1.63 \pm 0.12$ & $1.72 \pm 0.13$ & $1.41 \pm 0.12$ \\
\hline WISP2 (ng/ml) & $209.6 \pm 79.3$ & $305.6 \pm 70.1$ & $250.0 \pm 51.5$ \\
\hline SFRP5 (ng/ml) & $2.84 \pm 2.39$ & $4.01 \pm 4.52$ & $0.52 \pm 0.98^{\mathrm{a}, \mathrm{b}}$ \\
\hline SFRP4 (ng/ml) & $5.29 \pm 5.49$ & $7.43 \pm 9.72$ & $5.57 \pm 6.73$ \\
\hline Glucose $(\mathrm{mmol} / \mathrm{l})$ & $5.46 \pm 0.76$ & $5.56 \pm 0.80$ & $5.09 \pm 0.33^{\mathrm{a}, \mathrm{b}}$ \\
\hline Insulin (pmol/l) & $139.9 \pm 61.7$ & $145.6 \pm 83.8$ & $81.1 \pm 27.2^{\mathrm{a}, \mathrm{b}}$ \\
\hline HOMA & $5.4 \pm 2.3$ & $3.3 \pm 2.1^{\mathrm{a}}$ & $2.6 \pm 1.0^{\mathrm{a}}$ \\
\hline Adiponectin $(\mu \mathrm{g} / \mathrm{ml})$ & $8.5 \pm 5.0$ & $10.7 \pm 5.5$ & $13.6 \pm 6.4^{\mathrm{a}}$ \\
\hline Leptin $(\mu \mathrm{g} / \mathrm{l})$ & $32.1 \pm 13.1$ & $16.2 \pm 7.3^{\mathrm{a}}$ & $14.8 \pm 5.3^{\text {a }}$ \\
\hline Triglyceride (mmol/l) & $1.43 \pm 0.09$ & $1.03 \pm 0.11^{\mathrm{a}}$ & $1.18 \pm 0.17^{a}$ \\
\hline Cholesterol (mmol/l) & $5.05 \pm 0.15$ & $4.81 \pm 0.39$ & $5.53 \pm 0.28^{b}$ \\
\hline LDL-C (mmol/l) & $3.03 \pm 0.10$ & $2.99 \pm 0.22$ & $3.10 \pm 0.1$ \\
\hline $\mathrm{HDL}-\mathrm{C}(\mathrm{mmol} / \mathrm{l})$ & $1.02 \pm 0.16$ & $1.12 \pm 0.29$ & $1.42 \pm 0.30^{\mathrm{a}, \mathrm{b}}$ \\
\hline hs-CRP (g/l) & $5.8 \pm 0.8$ & $6.4 \pm 1.5$ & $4.3 \pm 1.5^{b}$ \\
\hline
\end{tabular}

Table 1 Clinical and biochemical variables of women with polycystic ovary syndrome (PCOS) and reference women and reference men.
Table 2 Insulin resistance and secretion parameters ${ }^{a}$.

\begin{tabular}{|lll|} 
& $\begin{array}{l}\text { Obese PCOS } \\
(\mathbf{n = 3 2})\end{array}$ & $\begin{array}{l}\text { Nonobese PCOS } \\
(\mathbf{n = 2 5 )}\end{array}$ \\
\hline HbA1c mmol/mol (\%) & $37 \pm 3.1(5.53 \pm 0.47)$ & $38 \pm 2.2(5.60 \pm 0.33)$ \\
\hline Matsuda Sensitivity Index & $2.39 \pm 0.30$ & $3.98 \pm 0.37 \mathrm{~b}$ \\
\hline FS-IGT-AIRg & $622 \pm 102$ & $514 \pm 100$ \\
\hline F-SIGT Sensitivity Index & $2.95 \pm 0.63$ & $3.55 \pm 0.57 \mathrm{c}$ \\
\hline FS-IGT Disposition Index & $1326 \pm 211$ & $1275 \pm 184$ \\
\hline FFA $(\mathrm{ng} / \mathrm{ml})$ & $0.619 \pm 0.043$ & $0.509 \pm 0.069$ \\
\hline FABP4 $(\mathrm{ng} / \mathrm{ml})$ & $45.8 \pm 6.0$ & $36.7 \pm 6.0$ \\
\hline TNF- $\alpha(\mathrm{pg} / \mathrm{ml})$ & $58.4 \pm 18.8$ & $45.5 \pm 17.5$ \\
\hline IL-6 $(\mathrm{pg} / \mathrm{ml})$ & $26.0 \pm 5.3$ & $15.6 \pm 3.2$ \\
\hline IL-1 $\beta(\mathrm{pg} / \mathrm{ml})$ & $42.2 \pm 13.0$ & $25.1 \pm 8.0$ \\
\hline Testosterone $(\mathrm{nmol} / \mathrm{l})$ & $0.028 \pm 0.008$ & $0.030 \pm 0.012$ \\
\hline SHBG $(\mathrm{nmol} / \mathrm{l})$ & $42.1 \pm 3.7$ & $27.5 \pm 2.5$ \\
\hline FAI & $9.1 \pm 0.7$ & $8.8 \pm 4.4$ \\
\hline DHEAS $(\mu \mathrm{mol} / \mathrm{l})$ & $4.15 \pm 0.58$ & $5.23 \pm 0.54$ \\
\hline
\end{tabular}

${ }^{a}$ Values (mean \pm SD) assessed by frequently sampled intravenous glucose tolerance test (FS-IGT), inflammatory markers, and sex steroids in women with polycystic ovary syndrome (PCOS)

${ }^{\mathrm{b}} \mathrm{p}<0.05$ as compared to obese PCOS

${ }^{c} \mathrm{p}=0.055$

parameters such as HOMA, Matsuda's insulin sensitivity index, or SI, the former explanation appears to be more likely.

To further elucidate the relationships among WNT5, body weight and insulin resistance, we wanted to investigate WNT proteins over a wide spectrum of insulin resistance and within a narrow range of body weight. Therefore, nonobese PCOS and weightmatched reference women were evaluated as a single group. In these women, WNT5 still correlated inversely with the parameters of adiposity (fat-mass and leptin) but not with insulin resistance. These findings indicated that serum WNT5 did not account for the large differences in insulin resistance between the PCOS vs. reference women. Taken altogether, it appears that anti-adipogenic effect of WNT is seen in women with or without PCOS. WNT signaling is related to the hyperinsulinemic response in PCOS patients. Since the reference women did not have OGTT, it
Table 3 Significant correlations between serum WNT 5, WISP2, secreted frizzled-related proteins 4 and 5 and biochemical parameters in PCOS women.

\begin{tabular}{llll} 
& & $\mathbf{r}$ & $\mathbf{p}$ \\
\multirow{2}{*}{ WNT 5 } & Insulin 90-min OGTT & 0.364 & 0.005 \\
& AUC Insulin OGTT & 0.293 & 0.027 \\
& IL6 & 0.292 & 0.047 \\
\multirow{2}{*}{ WISP2 } & SFRP4 & 0.516 & 0.00005 \\
& FABP4 & 0.383 & 0.021 \\
\hline SFRP5 & Cholesterol & -0.294 & 0.028 \\
& Apoprotein B & -0.306 & 0.022 \\
& TNF- $\alpha$ & -0.396 & 0.005 \\
& IL-1 $\beta$ & -0.433 & 0.002 \\
\hline \multirow{2}{*}{ SFRP4 } & DHEAS & 0.366 & 0.006 \\
\hline
\end{tabular}

Correlation coefficients and significance ( $\mathrm{p}$-values) calculated for Spearman correlations are presented

is not known whether WNT signaling relates to glucose-stimulated insulin response in women without PCOS.

Although serum WISP2 did not correlate with weight, fat-mass or insulin resistance, it correlated directly with FABP4. Fatty acid binding protein 4 chaperones free fatty acids released during lipolysis from the adipocytes into the circulation [29]. Serum FABP4 concentrations reflect the state of lipolysis in the adipose tissue [30]. As WNT signaling is anti-adipogenic and counters the actions of PPAR $\gamma$, the correlation observed between WISP2 and FABP4 is consistent with the role of WISP2 in WNT signaling. Interestingly, WISP2 was the most abundant of the all WNT related proteins. It is possible that the WISP2 measured in the circulation may have different biological functions than the cytosolic protein found in the adipose tissue [31].

It has been suggested that SFRP5 is an anti-inflammatory response generated in order to compensate for the increased WNT expression caused by obesity. Schulte et al. reported that SFRP5 protein is expressed in the white adipose tissue of lean as well as obese subjects [13]. Although serum SFRP5 concentrations tended to be higher in obese subjects than the lean subjects, the difference was not significant. In contrast with the 
findings of Schulte, Hu et al. demonstrated that in Chinese population obese subjects with or without diabetes had lower serum SFRP5 concentrations as compared to their respective lean controls [12]; similarly, women with PCOS had lower SFRP5 compared to their controls [32]. Serum SFRP5 concentrations of our PCOS patients were comparable to that published in the literature [32] while the serum SFRP5 of the reference women were much lower $[12,13,32]$. Although we are not clear about the cause of this finding, one explanation may be that the reference women were weight-matched with the PCOS patients and while they were not obese, they were overweight with average BMI of $29.0 \pm 6.3 \mathrm{~kg} / \mathrm{m}^{2}$. The control patients reported by $\mathrm{Hu}$ et al. had BMI of $22.7 \pm 3.2 \mathrm{~kg} / \mathrm{m}^{2}$ [32] and those reported by Schulte had BMI of $22.3 \pm 0.4 \mathrm{~kg} / \mathrm{m}^{2}$ [13]. Our findings suggest that regulation of SFRP5 differ in PCOS vs. reference subjects. Although most of the PCOS women had measurable serum SFRP5, 33\% of reference women had undetectable levels. Notably, nonobese PCOS women had 8-fold increase in serum SFRP5 as compared to weight matched reference women. These findings suggest that the compensatory defense mechanism of SFRP5 may not have been needed in the reference women [33]. When potential causes of higher serum SFRP5 in PCOS women were considered, obesity did not seem to be a candidate because there was no significant difference between the serum levels of nonobese vs. obese PCOS women. Insulin sensitivity/resistance did not seem to be important either because there was no relationship between serum SFRP5 and the detailed measures of insulin sensitivity or insulin secretion. Although experimental evidence indicates that WNT signaling or down regulation of SFRP5 was associated with pancreatic $\beta$-cell proliferation [34,35], we did not observe any relationship between $\beta$-cell function measured by OGTT and FS-IGT. Our results also differed from the report of Hu et al., which demonstrated that Chinese patients with Type 2 DM had lower serum SFRP5 than those with normal glucose tolerance [12]. Although testosterone has been reported to facilitate WNT signaling in adipocyte cultures [36], androgens did not seem to be a likely cause of high serum SFRP5 in PCOS because SFRP5 did not correlate with testosterone or DHEAS. On the other hand, inflammation seemed to be a likely regulator, because, in agreement with the findings of Ouchi et al., we observed significant inverse correlations between serum SFRP5 with inflammatory markers IL-1 $\beta$ and TNF- $\alpha$ [3]. In addition, SFRP5 correlated inversely with atherogenic lipids total cholesterol and apoprotein B, suggesting that SFRP5 may influence lipoprotein metabolism in the liver and possibly SFRP5 may play a protective role against development of cardiovascular disease. In summary, this study demonstrated that serum WNT5 concentrations related inversely to adipogenicity but directly with hyperinsulinemia in PCOS. Serum SFRP5 was significantly higher in PCOS and correlated inversely with the inflammatory markers and atherogenic lipids. These findings suggest that WNT signaling and WNT inhibitors play important roles in obesity, insulin resistance/secretion, inflammation, and cardiovascular risk in PCOS women. Additional research is needed to understand the mechanistic role of WNT signaling in regulation of metabolic risk factors.

\section{Conflict of Interest}

$\nabla$

The authors declare that there is no conflict of interest that would prejudice the impartiality of this scientific work.
References

1 Gustafson B, Hammarstedt A, Hedjazifar S, Smith U. Restricted adipogenesis in hypertrophic obesity: the role of WISP2, WNT, and BMP4. Diabetes 2013; 62: 2997-3004

2 Hammarstedt A, Hedjazifar S, Jenndahl L, Gogg S, Grunberg J, Gustafson $B$, Klimcakova E, Stich V, Langin D, Laakso M, Smith U. WISP2 regulates preadipocyte commitment and PPARgamma activation by BMP4. Proc Natl Acad Sci USA 2013; 110: 2563-2568

3 Ouchi N, Higuchi A, Ohashi K, Oshima Y, Gokce N, Shibata R, Akasaki $Y$, Shimono A, Walsh K. Sfrp5 is an anti-inflammatory adipokine that modulates metabolic dysfunction in obesity. Science 2010; 329: 454-457

4 Bilkovski R, Schulte DM, Oberhauser F, Gomolka M, Udelhoven M, Hettich MM, Roth B, Heidenreich A, Gutschow C, Krone W, Laudes M. Role of WNT-5a in the determination of human mesenchymal stem cells into preadipocytes. J Biol Chem 2010; 285: 6170-6178

5 Bilkovski R, Schulte DM, Oberhauser F, Mauer J, Hampel B, Gutschow C, Krone $W$, Laudes $M$. Adipose tissue macrophages inhibit adipogenesis of mesenchymal precursor cells via wnt-5a in humans. Int J Obes 2011; 35: 1450-1454

6 Oh DY, Olefsky JM. Medicine. Wnt fans the flames in obesity. Science 2010; 329: 397-398

7 Prestwich TC, Macdougald OA. Wnt/beta-catenin signaling in adipogenesis and metabolism. Curr Opin Cell Biol 2007; 19: 612-617

8 Rauch A, Mandrup S. Lighting the fat furnace without SFRP5. J Clin Invest 2012; 122: 2349-2352

9 Laudes $M$. Role of WNT signalling in the determination of human mesenchymal stem cells into preadipocytes. J Mol Endocrinol 2011; 46: R65-R72

10 Kawano Y, Kypta R. Secreted antagonists of the Wnt signalling pathway. J Cell Sci 2003; 116: 2627-2634

11 Mori H, Prestwich TC, Reid MA, Longo KA, Gerin I, Cawthorn WP, Susulic VS, Krishnan V, Greenfield A, Macdougald OA. Secreted frizzled-related protein 5 suppresses adipocyte mitochondrial metabolism through WNT inhibition. J Clin Invest 2012; 122: 2405-2416

$12 \mathrm{Hu}$ Z, Deng H, Qu H. Plasma SFRP5 levels are decreased in Chinese subjects with obesity and type 2 diabetes and negatively correlated with parameters of insulin resistance. Diabetes Res Clin Pract 2013; 99: 391-395

13 Schulte DM, Muller N, Neumann K, Oberhauser F, Faust M, Gudelhofer $H$, Brandt $B$, Krone $W$, Laudes $M$. Pro-inflammatory wnt5a and antiinflammatory sFRP5 are differentially regulated by nutritional factors in obese human subjects. PLoS ONE 2012; 7: e32437

14 Mahdi T, Hanzelmann S, Salehi A, Muhammed SJ, Reinbothe TM, Tang Y, Axelsson AS, Zhou Y, Jing X, Almgren P, Krus U, Taneera J, Blom AM, Lyssenko V, Esguerra JL, Hansson O, Eliasson L, Derry J, Zhang E, Wollheim CB, Groop L, Renstrom E, Rosengren AH. Secreted frizzled-related protein 4 reduces insulin secretion and is overexpressed in type 2 diabetes. Cell Metab 2012; 16: 625-633

15 Ehrmann DA. Polycystic ovary syndrome. N Engl J Med 2005; 352: 1223-1236

16 Ehrmann DA, Liljenquist DR, Kasza K, Azziz R, Legro RS, Ghazzi MN. Prevalence and predictors of the metabolic syndrome in women with polycystic ovary syndrome. J Clin Endocrinol Metab 2006; 91: 48-53

17 Glueck CJ, Papanna R, Wang P, Goldenberg N, Sieve-Smith L. Incidence and treatment of metabolic syndrome in newly referred women with confirmed polycystic ovarian syndrome. Metabolism 2003; 52: 908-915

18 Sam S, Dunaif A. Polycystic ovary syndrome: syndrome XX? Trends Endocrinol Metab 2003; 14: 365-370

19 Diamanti-Kandarakis E, Dunaif A. Insulin resistance and the polycystic ovary syndrome revisited: an update on mechanisms and implications. Endocr Rev 2012; 33: 981-1030

20 Lee SH, Demeterco C, Geron I, Abrahamsson A, Levine F, Itkin-Ansari P. Islet specific Wnt activation in human type II diabetes. Exp Diabetes Res 2008; 2008: 728763

21 Welters HJ, Kulkarni RN. Wnt signaling: relevance to beta-cell biology and diabetes. Trends Endocrinol Metab 2008; 19: 349-355

22 Christodoulides C, Lagathu C, Sethi JK, Vidal-Puig A. Adipogenesis and WNT signalling. Trends Endocrinol Metab 2009; 20: 16-24

23 Harp JB. New insights into inhibitors of adipogenesis. Curr Opin Lipidol 2004; 15: 303-307

24 Tang QQ Lane MD. Adipogenesis: from stem cell to adipocyte. Annu Rev Biochem 2012; 81: 715-736

25 Yang X, Jansson PA, Nagaev I, Jack MM, Carvalho E, Sunnerhagen KS, Cam MC, Cushman SW, Smith U. Evidence of impaired adipogenesis in insulin resistance. Biochem Biophys Res Commun 2004; 317 : 1045-1051 
26 Fujino T, Asaba H, Kang MJ, Ikeda Y, Sone H, Takada S, Kim DH, Ioka $R X$, Ono M, Tomoyori H, Okubo M, Murase T, Kamataki A, Yamamoto J, Magoori K, Takahashi S, Miyamoto Y, Oishi H, Nose M, Okazaki M, Usui S, Imaizumi K, Yanagisawa M, Sakai J, Yamamoto TT. Low-density lipoprotein receptor-related protein 5 (LRP5) is essential for normal cholesterol metabolism and glucose-induced insulin secretion. Proc Natl Acad Sci USA 2003; 100: 229-234

27 Schinner S, Ulgen F, Papewalis C, Schott M, Woelk A, Vidal-Puig A, Scherbaum WA. Regulation of insulin secretion, glucokinase gene transcription and beta cell proliferation by adipocyte-derived Wnt signalling molecules. Diabetologia 2008; 51: 147-154

28 Karakas SE, Kim K, Duleba AJ. Determinants of impaired fasting glucose versus glucose intolerance in polycystic ovary syndrome. Diabetes Care 2010; 33: 887-893

29 Karakas SE, Almario RU, Kim K. Serum fatty acid binding protein 4, free fatty acids, and metabolic risk markers. Metabolism 2009; 58 : $1002-1007$

30 Comerford KB, Buchan W, Karakas SE. The Effects of Weight Loss on FABP4 and RBP4 in Obese Women with Metabolic Syndrome. Horm Metab Res 2014; 46: 224-231

31 Grunberg JR, Hammarstedt A, Hedjazifar S, Smith $U$. The Novel Secreted Adipokine WNT1-Inducible-Signaling Pathway Protein2/WISP2 is a Mesenchymal Cell Activator of Canonical WNT. J Biol Chem 2014; 289: 6899-6907
32 Hu W, Li L, Yang M, Luo X, Ran W, Liu D, Xiong Z, Liu H, Yang G. Circulating Sfrp5 is a signature of obesity-related metabolic disorders and is regulated by glucose and liraglutide in humans. J Clin Endocrinol Metab 2013; 98: 290-298

33 Lee H, Bae S, Yoon Y. The anti-adipogenic effects of (-)-epigallocatechin gallate are dependent on the WNT/beta-catenin pathway. J Nutr Biochem 2013; 24: 1232-1240

34 Papadopoulou S, Edlund $H$. Attenuated Wnt signaling perturbs pancreatic growth but not pancreatic function. Diabetes 2005; 54: 28442851

35 Rebuffat SA, Oliveira JM, Altirriba J, Palau N, Garcia A, Esteban Y, Nadal $B$, Gomis $R$. Downregulation of Sfrp5 promotes beta cell proliferation during obesity in the rat. Diabetologia 2013; 56: 2446-2455

36 Singh R, Artaza JN, Taylor WE, Braga M, Yuan X, Gonzalez-Cadavid NF, Bhasin S. Testosterone inhibits adipogenic differentiation in 3T3-L1 cells: nuclear translocation of androgen receptor complex with betacatenin and T-cell factor 4 may bypass canonical Wnt signaling to down-regulate adipogenic transcription factors. Endocrinology 2006; 147: $141-154$ 